\title{
vector control of Induction machine using distributed delay neural flux observers
}

\author{
Daniel Igbokwe \\ Dept. of Elect \& Elect Engr. \\ University of Lagos, Akoka, Nigeria.
}

\author{
Adeola Balogun \\ Dept. of Elect \& Elect Engr. \\ University of Lagos, Akoka, Nigeria.
}

\begin{abstract}
Vector control of induction motor, has gained dominance due to the improvement of computing hardware and the extended use of induction motor beyond industrial uses such as the electric vehicle, and automated medical machinery. The removal of the flux sensors necessitates the use of estimators to estimate the flux of induction machine. This paper use the artificial neural network to estimate the flux of the induction motor along the direct and quadrature axis, and make it available for feedback. Distributed delay neural networks which are more suited for time series problems is used in place of plain feed forward neural networks.
\end{abstract}

\section{Introduction}

Various control methods to achieve the control of the induction machine include; the field oriented control, which may include the direct and indirect field oriented control; the rotor and the stator flux oriented control; the direct open loop control, which is characterized by its sheer simplicity; a the direct torque control; and the model reference adaptive system [1] [2]. All of which which are constantly evolving as new methods and technologies for control emerge.

Field oriented control is widely used for control of induction motor drives. In this control scheme, an array of sensors is used, including flux sensors. However, a flux sensors may prove expensive or outright calculative estimation may prove slightly inaccurate. In response to this problem, several sensorless schemes have been proposed, most of which utilize neural networks. [3] [4].
In most of the sensorless vector control schemes which utilize neural networks, the feed forward neural network is used, with offline training done using experimental or simulation data [5]. Some schemes further improve by utilizing online training methods, yet still with plain feed forward neural networks [6].

In this paper, the feed forward neural network is replaced with recurrent neural network, which accounts for the temporal dimension of the speed of the induction machine.

\section{Induction machine model}

The stator and rotor voltage equations of the induction machine in $q-d$ arbitrary reference frame as given in the equations below.

The stator and rotor voltages are given as

$$
\begin{gathered}
V_{q s}=r_{s} i_{q s}+\omega \lambda_{d s}+p \lambda_{q s} \\
V_{d s}=r_{s} i_{d s}-\omega \lambda_{q s}+p \lambda_{d s} \\
V_{q r}^{\prime}=r_{r}^{\prime} i_{q r}^{\prime}+\left(\omega-\omega_{r}\right) \lambda_{d r}^{\prime}+p \lambda_{q r}^{\prime} \\
V_{d r}^{\prime}=r_{r}^{\prime} i_{d r}^{\prime}-\left(\omega-\omega_{r}\right) \lambda_{q r}^{\prime}+p \lambda_{d r}^{\prime}
\end{gathered}
$$

The flux linkages in both the stator and rotor also expressed as

$$
\begin{aligned}
& \lambda_{q s}=L_{l s} i_{q s}+L_{M}\left(i_{q s}+i_{q r}^{\prime}\right) \\
& \lambda_{d s}=L_{l s} i_{d s}+L_{M}\left(i_{d s}+i_{d r}^{\prime}\right) \\
& \lambda_{q r}^{\prime}=L_{l r}^{\prime} i_{q r}^{\prime}+L_{M}\left(i_{q s}+i_{q r}^{\prime}\right) \\
& \lambda_{d r}^{\prime}=L_{l r}^{\prime} i_{d r}^{\prime}+L_{M}\left(i_{d s}+i_{d r}^{\prime}\right)
\end{aligned}
$$

The $q-d$ components of stator and rotor voltage are transformed values of the $a b c$ reference stator 
and rotor voltages. The electromagnetic toque is finally given as

$$
T_{e}=\left(\frac{3}{2}\right)\left(\frac{P}{2}\right)\left(\lambda_{q r}^{\prime} i_{d r}^{\prime}-\lambda_{d r}^{\prime} i_{q r}^{\prime}\right)
$$

\section{Rotor Flux Field-Oriented Control}

Using the equations $1-8$ The Induction machine model can be compared with a control system of the form $A X+B U=\dot{X}$.

$$
\begin{gathered}
{\left[\begin{array}{c}
i_{q s}^{\cdot} \\
i_{d s} \\
\lambda_{q s} \\
\lambda_{d s}
\end{array}\right]=} \\
{\left[\begin{array}{cccc}
\frac{-r_{s}}{L_{o}} & -\omega & \frac{r_{r}^{\prime} L_{m}}{L_{r}^{\prime 2} L_{o}} & \frac{-\omega_{r} L_{m}}{L_{r}^{\prime} L_{o}} \\
-\omega & \frac{-r_{s}}{L_{o}} & \frac{\omega_{r} L_{m}}{L_{r}^{\prime} L_{o}} & \frac{r_{r}^{\prime} L_{m}}{L_{r}^{\prime 2} L_{o}} \\
\frac{r_{r}^{\prime} L_{m}}{L_{r}} & 0 & \frac{-r_{r}^{\prime}}{L_{r}} & \left(\omega-\omega_{r}\right) \\
0 & \frac{r_{r}^{\prime} L_{m}}{L_{r}} & \left(\omega-\omega_{r}\right) & \frac{-r_{r}^{\prime}}{L_{r}}
\end{array}\right] *\left[\begin{array}{c}
i_{q s} \\
i_{d s} \\
\lambda_{q s} \\
\lambda_{d s}
\end{array}\right]+} \\
{\left[\begin{array}{cccc}
1 \\
1 \\
1 \\
1
\end{array}\right]\left[\begin{array}{llll}
V_{q s} & V_{d s} & 0 & 0
\end{array}\right]}
\end{gathered}
$$

The rotor flux orientation is obtained by aligning the rotor flux vector along the $d$ axis i.e

$$
\lambda_{q r}=0, \text { and } \lambda_{d r}=\lambda_{r}
$$

using the above equation 11 we can construct the control loops following from the state space equation as follows.

$$
\begin{aligned}
& \text { given that } p=\frac{d u}{d t} \\
& p L_{o} i_{q s}=V_{q s}-r_{s} i_{q s}-\omega L_{o} i_{d s}-\frac{\omega_{r} L_{m}}{L_{r}} \lambda_{d r} \\
& p L_{o} i_{d s}=V_{d s}-r_{s} i_{d s}+\omega L_{o} i_{q s}+\frac{r_{r} L_{m}}{L_{r}^{2}} \lambda_{d r}
\end{aligned}
$$

Introducing $\delta$ terms from equations $(12)-(13)$

$$
\begin{gathered}
\delta_{q s}=p L_{o} i_{q s}+r_{s} i_{q s}=\left(p L_{o}+r_{s}\right) i_{q s}= \\
K\left(i_{q s}^{*}-i_{q s}\right)=V_{q s}-\omega L_{o} i_{d s}-\frac{\omega_{r} L_{m}}{L_{r}} \lambda_{d r}
\end{gathered}
$$

$$
\begin{gathered}
\delta_{d s}=p L_{o} i_{d s}+r_{s} i_{d s}=\left(p L_{o}+r_{s}\right) i_{d s}= \\
K\left(i_{d s}^{*}-i_{d s}\right)=V_{d s}+\omega L_{o} i_{q s}+\frac{r_{r} L_{m}}{L_{r}^{2}} \lambda_{d r}
\end{gathered}
$$

where the operator $K$ is defined as a PI controller

$$
K=\left[K_{P}+\frac{K_{I}}{S}\right]
$$

From equations (14)and(15) the reference voltage is obtained by making $V_{q s}$ and $V_{d s}$ the subjects of the formula.

$$
\begin{gathered}
V_{q s}^{*}=\delta_{q s}+\omega L_{o} i_{d s}+\frac{\omega_{r} L_{m}}{L_{r}} \lambda_{d r} \\
V_{d s}^{*}=\delta_{d s}-\omega L_{o} i_{q s}-\frac{r_{r} L_{m}}{L_{r}^{2}} \lambda_{d r}
\end{gathered}
$$

The flux control loops can also be obtained in a similar manner, from the last two state space equations

$$
\begin{aligned}
& L_{r}^{\prime} p \lambda q r=-r_{r}^{\prime} \lambda_{q r}+r_{r}^{\prime} L_{m} i_{q s}+\left(\omega-\omega_{r}\right) \lambda_{d r} \\
& L_{r}^{\prime} p \lambda d r=-r_{r}^{\prime} \lambda_{d r}+r_{r}^{\prime} L_{m} i_{d s}+\left(\omega-\omega_{r}\right) \lambda_{q r}
\end{aligned}
$$

Introducing $\delta$ terms from equations $(19)-(20)$

$$
\begin{aligned}
& \delta_{\lambda q r}=\left(L_{r}^{\prime} p+r_{r}^{\prime}\right) \lambda_{q r}= \\
& K_{r}\left(\lambda_{q r}-\lambda_{q r}^{*}\right)=r_{r}^{\prime} L_{m} i_{q s}+\left(\omega-\omega_{r}\right) \lambda_{d r}
\end{aligned}
$$

remembering that for rotor flux oriented control $\lambda_{q r}=0$

$$
\begin{aligned}
\delta_{\lambda d r}=\left(L_{r}^{\prime} p+r_{r}^{\prime}\right) & \lambda_{d r}= \\
& K_{r}\left(\lambda_{d r}-\lambda_{d r}^{*}\right)=r_{r}^{\prime} L_{m} i_{d s}^{*}
\end{aligned}
$$

The reference stator current along the $\mathrm{d}$ axis is given as

$$
i_{d s}^{*}=\frac{\delta_{\lambda d r}}{r_{r}^{\prime} L_{m}}
$$

To obtain the reference current along the $q$ axis, the torque equation is first written as

$$
\begin{gathered}
\frac{d \omega_{r}}{d t}=\frac{P}{2 J}\left[T_{e}-T_{L}\right]+B \omega_{r} \\
T_{e}=\frac{3}{4} \frac{P L_{m}}{L_{r}}\left[\lambda_{d r} i_{q s}^{*}\right] \\
i . e \delta_{\omega_{r}}=K_{\omega}\left(\omega_{r}^{*}-\omega_{r}\right)=\frac{3}{4} \frac{P L_{m}}{L_{r}}\left[\lambda_{d r} i_{q s}^{*}\right]-T_{L}
\end{gathered}
$$




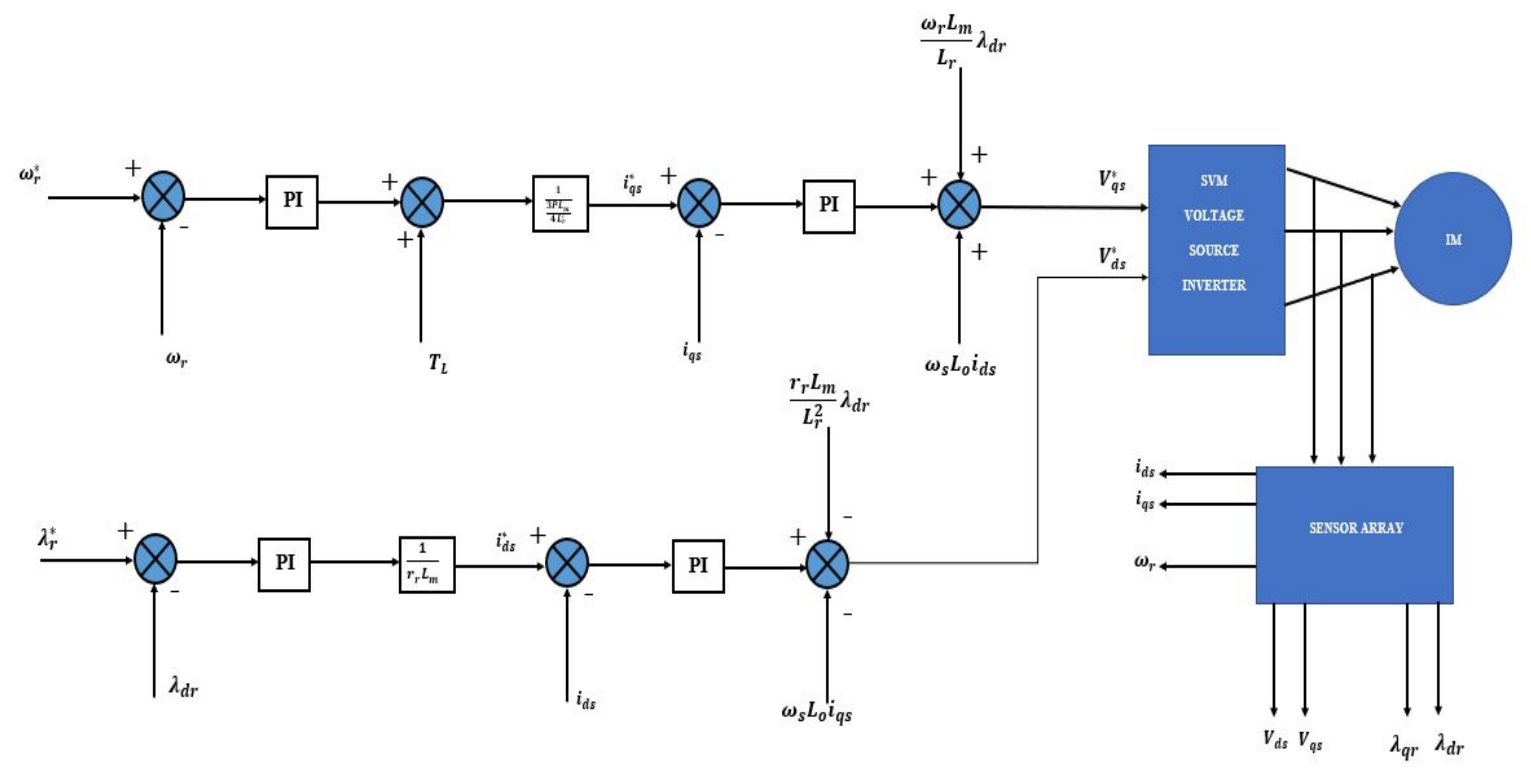

Figure 1: Control Diagram of Rotor flux Field oriented control of Induction Machine

The reference current along the $\mathrm{q}$ axis is then given as

$$
i_{q s}^{*}=\frac{\delta_{\omega_{r}}-T_{L}}{\frac{3}{4} \frac{P L_{m}}{L_{r}} \lambda_{d r}^{*}}
$$

Figure 1. above Represents the overall architecture of the rotor flux field oriented control of the induction machine.

\section{Sensorless Speed Estima- tion}

\section{IV.I FeedForward Neural Networks}

From the Figure 1. above of the control diagram of the rotor flux field oriented control, one of the feedback components is the flux of the machine. Instead a Neural flux estimator may be used in place of a flux sensor. One of the methods of flux estimation is the use of feed forward neural networks.

The Feedforward neural network is able to estimate the speed due to it's ability to act as a function approximator [7]. For most speed estimation using feed forward neural networks, the network is first trained offline using simulation, and real world data [8]. The feed forward neural network
, unfortunately has no temporal dimension to it, as it forms a static associative memory based on the training data. It is due to this fact that a neural network incorporating dynamic temporal response would prove superior in the speed estimation of the induction machine

\section{IV.II Distributed delay Neural Net- works}

The distributed delay neural network responds temporally to an externally applied input signal.This enables the networks to develop state representations, which make them well suited for use in a myriad of applications such as nonlinear prediction and modeling, and plant control, and automobile engine diagnostics. In summary, recurrent networks offer a better alternative to the static feedforward networks.[7]. Figure 2 below shows a diagram of recurrent network with delays shown

\section{Training the Neural net- work}

The training of the distributed delay neural network utilizes the Levenberg-Marquadt algorithm , 


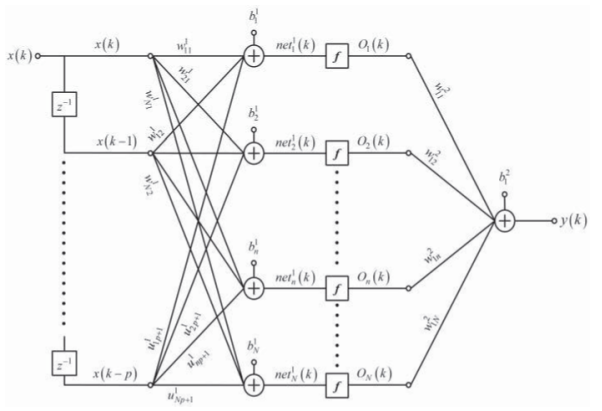

Figure 2: Simple Distributed Delay Neural Network

which is an improvement to the traditional back propagation algorithm.

\section{V.I Summary of Levenberg- Marquadt Training algorithm}

1. Present all input to the network, and compute the output. Subsequently compute the errors over all input $V(x)$

2. Compute the Jacobian matrix which takes the form

$$
J(x)=\left[\begin{array}{cccc}
\frac{\partial e_{1}(x)}{\partial x_{1}} & \frac{\partial e_{1}(x)}{\partial x_{2}} & \ldots & \frac{\partial e_{1}(x)}{\partial x_{n}} \\
\frac{\partial e_{2}(x)}{\partial x_{1}} & \frac{\partial e_{2}(x)}{\partial x_{2}} & \ldots & \frac{\partial e_{2}(x)}{\partial x_{n}} \\
\vdots & \vdots & \ddots & \vdots \\
\frac{\partial e_{N}(x)}{\partial x_{1}} & \frac{\partial e_{N}(x)}{\partial x_{2}} & \ldots & \frac{\partial e_{2}(x)}{\partial x_{n}}
\end{array}\right]
$$

where $e_{j}(x)$ represents the error at $j t h$ neuron

3. The term $\Delta x$ is calculated using two learning parameters $\mu$ and $\beta$

$$
\Delta x=\left[J^{T}(x) J(x)+\mu I\right]^{-1} J^{T}(x) e(x)
$$

4. recalculate the sum of squares error using $x+$ $\Delta x$.

(a) if this new sum is less than the error in step 1 , reduce $\mu$ by $\beta$, let $x=x+\Delta x$, and go back to step 1

(b) else if this sum is greater, increase $\mu$ by $\beta$ and go back to step 3
The training is assumed to have converged, and can be terminated if the norm given by $\nabla V(x)=J^{T}(x) e(x)$ has reached a predefined level

\section{Results and Discussion}

The neural flux observer is trained using simulation data from a MATLAB/SIMULINK environment. After satisfactory gradient is achieved, the neural network is placed in the simulation environment. The machine used in the simulation is $460 \mathrm{HP} / 1000 \mathrm{KW}$ three phase squirrel-cage induction machine. The machine is driven by a space vector pulse width modulated inverter which receives voltage commands from the output of the control system. The parameters are shown in Table 1 below

The gradient performance of the neural network after training is shown in the figure 3 . The flux outputs of the neural observer is shown in fig 4 \& 5.
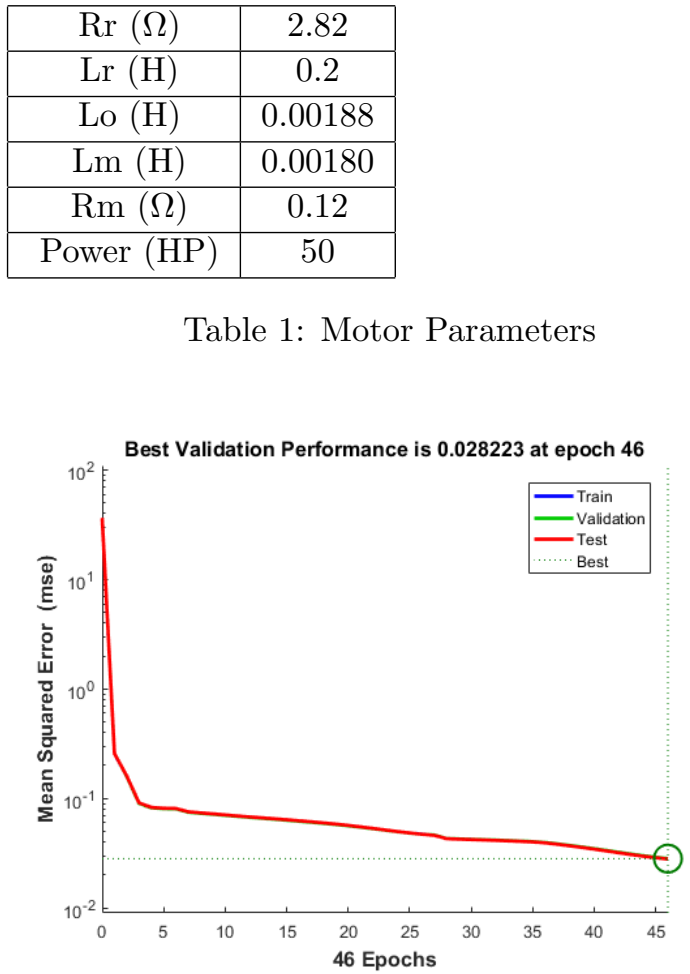

Figure 3: Gradient Performance plot of Neural Network after training 


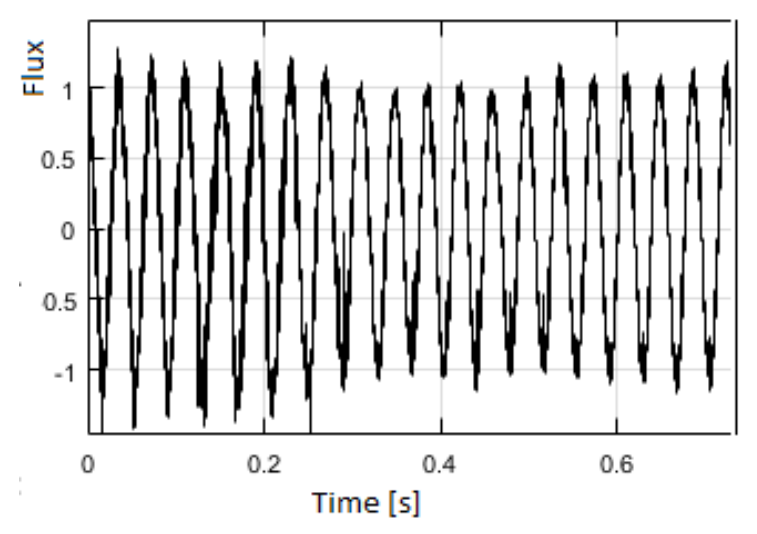
Figure 4: Neural observer flux output in Q. axis

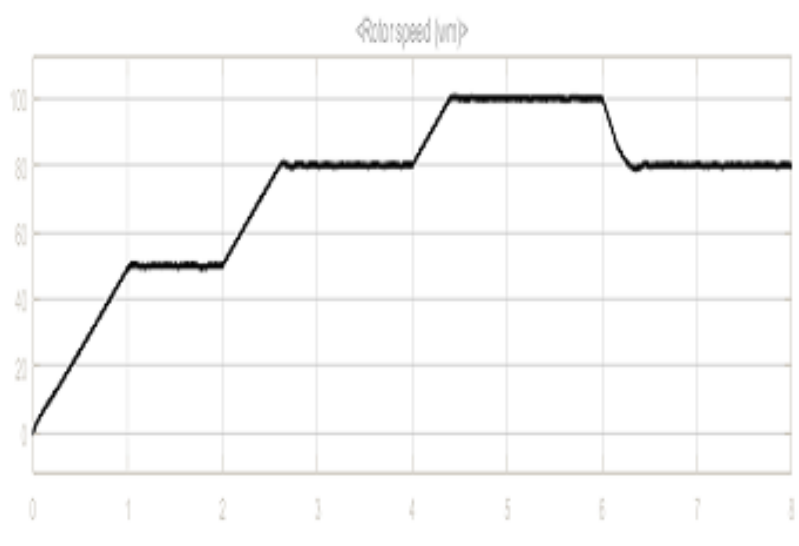

Figure 6: speed of Induction Machine

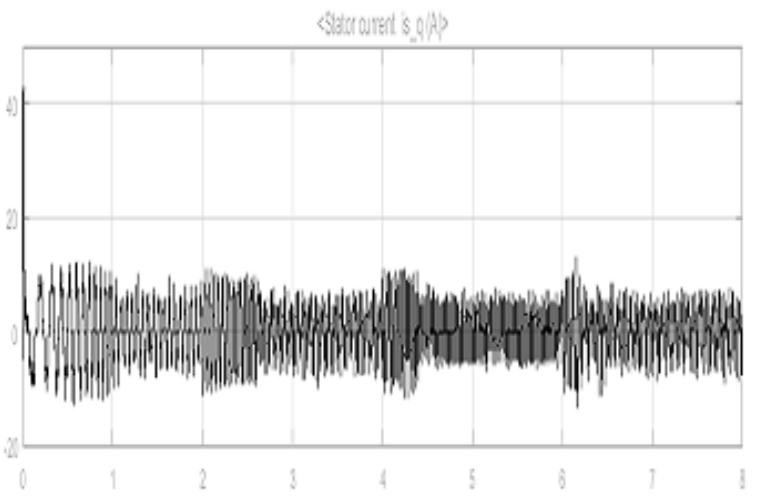

Figure 7: Stator current in the Q-Axis

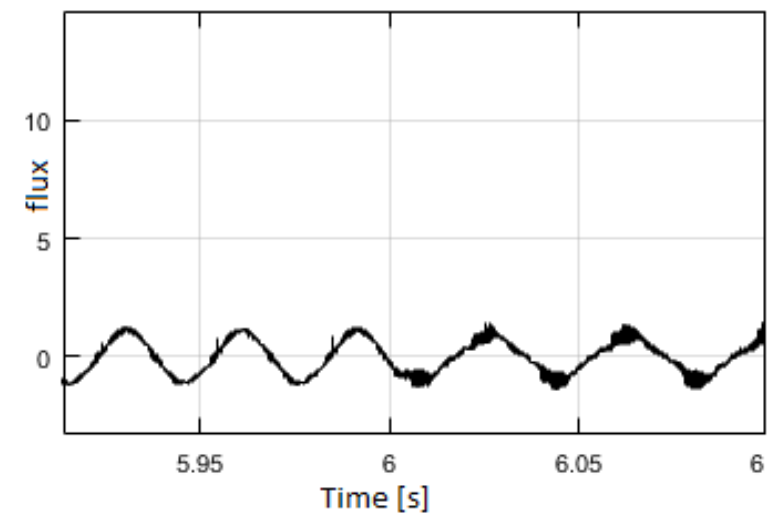

Figure 5: Neural observer flux output in Direct axis

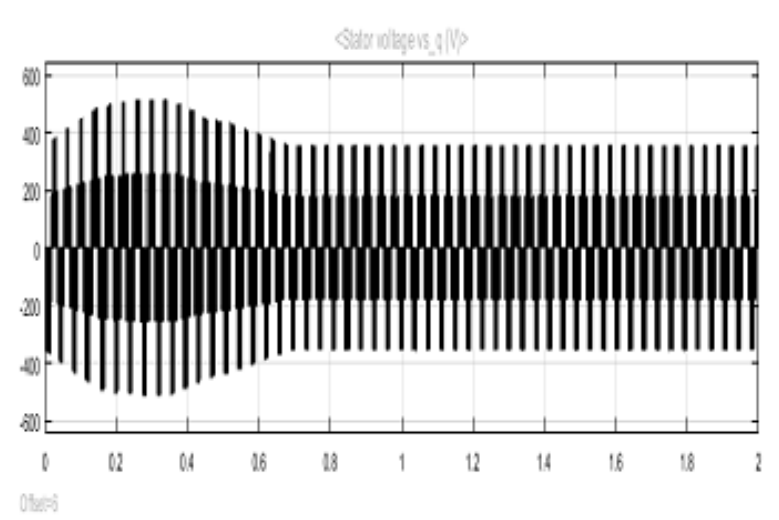

Figure 8: Stator voltage in the Q-Axis 


\section{Conclusion}

A Vector control for the induction machine was developed using a neural flux observer in place of actual sensors. The system was simulated using a distributed delay neural network for the flux observer which provided feedback to the outer and inner control loops, providing similar and accurate speed responses as in the case of sensor based feedback. Furthermore, the use of the flux observer limited the sensory input to just speed, voltage and current.

\section{References}

[1] R. Kumar, P. Syam, S. Das, and A. K. Chattopadhyay, "Review on model reference adaptive system for sensorless vector control of induction motor drives," IET Electric Power Applications, vol. 9, pp. 496-511, aug 2015.

[2] R. H. Kumar, A. Iqbal, and N. C. Lenin, "Review of recent advancements of direct torque control in induction motor drives - a decade of progress," IET Power Electronics, vol. 11, pp. 1-15, jan 2018.

[3] H. Kubota and K. Matsuse, "Speed sensorless field-oriented control of induction motor with rotor resistance adaptation," IEEE Transactions on Industry Applications, vol. 30, no. 5, pp. 1219-1224, 1994.

[4] Y.-R. Kim, S.-K. Sul, and M.-H. Park, "Speed sensorless vector control of induction motor using extended kalman filter," IEEE Transactions on Industry Applications, vol. 30, no. 5, pp. 1225-1233, 1994.

[5] S.-H. Kim, T.-S. Park, J.-Y. Yoo, and G.-T. Park, "Speed-sensorless vector control of an induction motor using neural network speed estimation," IEEE Transactions on Industrial Electronics, vol. 48, pp. 609-614, jun 2001.

[6] X. Sun, L. Chen, Z. Yang, and H. Zhu, "Speedsensorless vector control of a bearingless induction motor with artificial neural network inverse speed observer," IEEE/ASME Transactions on Mechatronics, vol. 18, pp. 1357-1366, aug 2013.
[7] S. Haykin, Neural Networks: A Comprehensive Foundation. Prentice Hall, 1999.

[8] B. Bose, M. G. Simoes, D. Crecelius, K. Rajashekara, and R. Martin, "Speed sensorless hybrid vector controlled induction motor drive," in IAS '95. Conference Record of the 1995 IEEE Industry Applications Conference Thirtieth IAS Annual Meeting, IEEE, 1995.

[9] X. dong Sun, H. qiu Zhu, and W. Pan, "Decoupling control of bearingless permanent magnet-type synchronous motor using artificial neural networks-based inverse system method," International Journal of Modelling, Identification and Control, vol. 8, no. 2, p. 114, 2009.

[10] S. M. Gadoue, D. Giaouris, and J. W. Finch, "MRAS sensorless vector control of an induction motor using new sliding-mode and fuzzylogic adaptation mechanisms," IEEE Transactions on Energy Conversion, vol. 25, pp. 394402, jun 2010.

[11] M. Barut, S. Bogosyan, and M. Gokasan, "Speed-sensorless estimation for induction motors using extended kalman filters," IEEE Transactions on Industrial Electronics, vol. 54, pp. 272-280, feb 2007.

[12] S. M. N. Hasan and I. Husain, "A luenberger sliding mode observer for online parameter estimation and adaptation in highperformance induction motor drives," IEEE Transactions on Industry Applications, vol. 45, no. 2, pp. 772-781, 2009.

[13] A. Balogun and O. Ojo, "Natural variable simulation of induction machines," in AFRICON 2009, IEEE, sep 2009. 